\title{
Fungos e aflatoxinas no arroz: ocorrência e significado na saúde do consumidor
} Fungi and aflatoxins in rice: occurrence and significance to consumer health

\author{
Aline Machado Katsurayama ${ }^{1 *}$, Marta Hiromi Taniwaki ${ }^{1}$ \\ 1 Instituto de Tecnologia de Alimentos (ITAL), Centro de Ciência e Qualidade de Alimentos (CCQA), Laboratório de Microbiologia, Campinas/SP - Brasil \\ *Corresponding Author \\ Aline Machado Katsurayama, Instituto de Tecnologia de Alimentos (ITAL), Centro de Ciência e Qualidade de Alimentos (CCQA), Laboratório de \\ Microbiologia, Av. Brasil, 2880, CEP: 13070-178, Campinas/SP - Brasil, e-mail: amkatsurayama@yahoo.com.br
}

Cite as: Fungi and aflatoxins in rice: occurrence and significance to consumer health. Braz. J. Food Technol., v. 20, e2017006, 2017.

Received: Jan. 27, 2017; Accepted: Apr. 12, 2017

\section{Resumo}

O arroz é um dos cereais mais consumidos no Brasil e no mundo. Devido ao grande impacto do consumo de arroz na população, estudos sobre a qualidade deste produto são de grande importância. É um ótimo substrato para a produção de micotoxinas e, quando os fungos toxigênicos encontram condições de crescer e produzir toxinas, estes as produzem em grandes quantidades. Embora não seja comum a presença de micotoxinas, existem alguns relatos sobre a ocorrência de aflatoxinas e fungos aflatoxigênicos no arroz. O presente artigo é uma revisão sobre os aspectos gerais do arroz, sua produção, ocorrência de fungos, aflatoxinas e micotoxinas no Brasil e no mundo, bem como sobre a redução de aflatoxinas durante o processamento do arroz.

Palavras-chave: Arroz; Produção; Aflatoxinas; Fungos; Micotoxinas.

\section{Abstract}

Rice is one of the cereals most consumed in Brazil and in the world. Due to the significant impact of rice consumption on the population, studies regarding its quality are of great importance. It is an excellent substrate for fungal growth and mycotoxin production, so when toxigenic fungi find conditions to grow and produce toxins, they produce large quantities. Although the presence of mycotoxins is not common in rice, some previous reports have shown the presence of aflatoxins and aflatoxigenic fungi in rice. Thus the present article is a review concerning the general aspects of rice, its production, and the occurrence of fungi, aflatoxins and other mycotoxins in Brazil and in the world, and also the reduction of aflatoxin during rice processing.

Keywords: Rice; Production; Aflatoxins; Fungi; Mycotoxins.

\section{Introdução}

O arroz é um dos cereais mais consumidos e faz parte da dieta de milhões de pessoas. A garantia de qualidade e sanidade do arroz é de máxima importância, porque qualquer contaminante presente poderá afetar a saúde do consumidor, principalmente nos países como o Brasil, onde o arroz faz parte da dieta diária.

Um fator preocupante do arroz é que este cereal é um ótimo substrato para a produção de micotoxinas e os fungos as produzem em grandes quantidades (KJER et al., 2010). As micotoxinas que já foram encontradas nas amostras de arroz são: citrinina, luteosquirina, cicloclorotina, islanditoxina, rugulosina, ocratoxina $A$, aflatoxinas, desoxinivalenol, fumonisinas e zearalenona, entre outras (FREDLUND et al., 2009; AYDIN et al., 2011; ALMEIDA et al., 2012).

Na presente revisão, serão tratados os aspectos gerais do arroz, sua produção, ocorrência de fungos, aflatoxinas e micotoxinas no Brasil e no mundo, bem como a redução de aflatoxinas durante o processamento do arroz.

\subsection{Aspectos gerais do arroz}

O arroz (Oryza sativa) originou-se na Ásia e difundiu-se para os outros continentes, desempenhando um importante papel econômico e social, por ser uma das principais fontes 
de carboidrato e alimento básico predominante na dieta mundial (MCLEAN et al., 2002).

É uma planta herbácea pertencente à família das gramíneas, que necessita de calor e umidade para crescer. Pode medir de $30 \mathrm{~cm}$ a $180 \mathrm{~cm}$ de altura, é lisa, tem pontos de floração e hastes arredondadas, nas quais são produzidos os grãos de arroz (MCLEAN et al., 2002).

O grão de arroz (Figura 1) é composto por: (i) casca, constituída pela pálea e a lema, correspondendo a 20\% do peso do grão; (ii) cariopse, constituída pelo pericarpo, tegumento, aleuroma, endosperma de amido; (iii) embrião, que é composto pelo escutelo, epiblasmo, plúmula e radícula (WALTER et al., 2008).

O arroz é classificado pelo Ministério da Agricultura Pecuária e Abastecimento (MAPA) do Brasil, de acordo com a Instrução Normativa N. ${ }^{\circ} 6$ de 16/02/2009, como arroz em casca natural e beneficiado (integral, polido, parboilizado), sendo dividido em classes: longo fino, longo, médio, curto e misturado. Após a colheita, o arroz é seco para atingir o grau de umidade de $12 \%$, armazenado em silos e encaminhado para o beneficiamento (BRASIL, 2009).

O consumo médio mundial é de $60 \mathrm{~kg} /$ pessoa/ano, sendo que, em países asiáticos, onde são produzidos 90\% da produção mundial de arroz, as médias são mais elevadas, situadas entre $100 \mathrm{~kg}$ e $150 \mathrm{~kg} /$ pessoa/ano. Na América Latina, são consumidos, em média, 30 kg/pessoa/ano, pelo que o Brasil destaca-se como grande consumidor, com média de 45 kg/pessoa/ano (FAO, 2016).

\subsection{Produção de arroz no Brasil e no mundo}

O Brasil é o nono maior produtor mundial, destacando-se como o maior produtor fora do continente asiático. A produção mundial de arroz tem apresentado

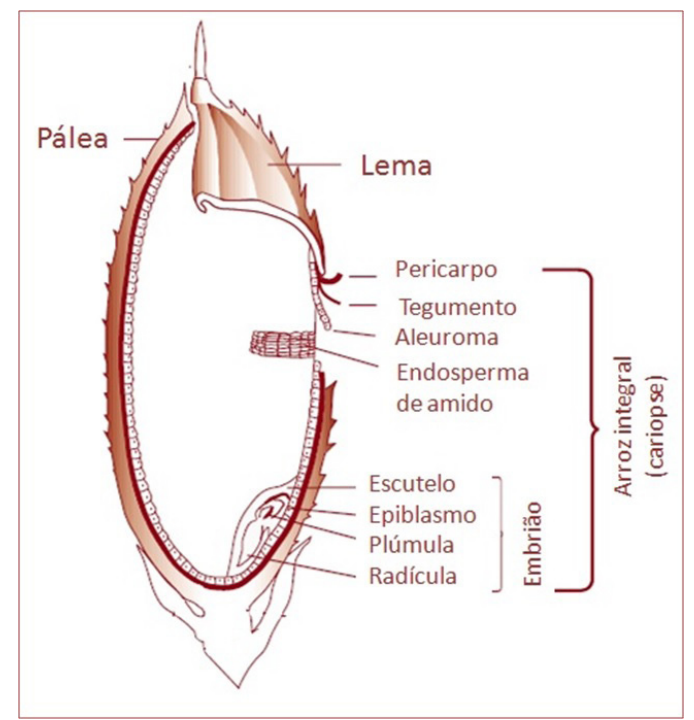

Figura 1. Estrutura do grão de arroz (MCLEAN et al., 2002). certa estagnação nos últimos anos devido a efeitos climáticos do El Niño e La Niña (Figura 2). A produção brasileira de arroz em casca, na safra de 2015/2016, foi de 7,5 milhões de toneladas, decaindo 11,6\% em relação à safra do ano anterior (FAO, 2016). A estimativa de produção brasileira de arroz em casca para a safra 2016/2017 é de 11.506,6 mil toneladas (CONAB, 2016).

Existem dois tipos de ecossistemas de plantio de arroz no Brasil: (i) ecossistema de várzeas (irrigado), o qual é irrigado por inundação controlada, e (ii) ecossistema de terras altas (sequeiro), em que o arroz pode ser produzido sem irrigação (água totalmente dependente da precipitação pluvial) ou com irrigação suplementar por aspersão, o que diminui o estresse hídrico da planta, propiciando maior qualidade do grão (MCLEAN et al., 2002). Apesar de o arroz ser uma cultura comum em quase todo o país, a maior parte da produção ocorre em cinco Estados: Rio Grande do Sul concentra a maior parte da produção (66,5\%), seguido de Santa Catarina $(8,6 \%)$ e Tocantins $(4,7 \%)$, sendo que, nestes três Estados, predomina o arroz irrigado; seguem Maranhão (5,3\%) e Mato Grosso (4,4\%), onde predomina o arroz de sequeiro. No Nordeste, especialmente no Estado do Ceará, o arroz se concentra em perímetros de irrigação. Uma pequena quantidade também é produzida nos Estados por onde passa o Rio São Francisco, como Bahia, Sergipe, Alagoas e Pernambuco, sendo que essas áreas recebem a irrigação pelo rio (CONAB, 2016).

O grande volume produzido nos Estados do Rio Grande do Sul e de Santa Catarina é considerado estabilizador para o mercado brasileiro de arroz e garante o seu suprimento à população brasileira. Quase todo o arroz produzido nestes dois Estados apresenta grãos da classe longo-fino e com alta qualidade de cocção, características exigidas

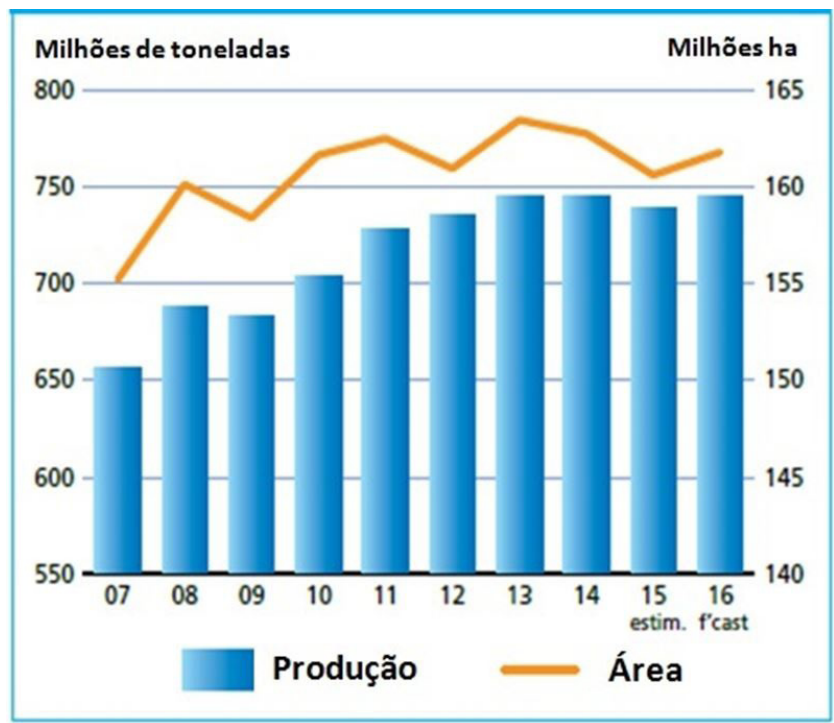

Figura 2. Produção de arroz em casca e área (FAO, 2016). 
Fungos e aflatoxinas no arroz: ocorrência e significado na saúde do consumidor

Katsurayama, A. M.; Taniwaki, M. H.

pelo mercado brasileiro, principalmente nas Regiões Sul e Sudeste (SOSBAI, 2014).

Boa parte do arroz de terras altas é cultivada no cerrado, na região central do Brasil. Nesta região, ocorre a rotação de cultura do arroz com pasto ou soja (dois anos de cultivo de arroz, dois anos de pasto ou soja), para evitar o "colapso de rendimento" que ocorre com o cultivo contínuo de arroz. Após dois anos de cultivo de arroz, o rendimento declina cerca de $10 \%$ e, no terceiro ano, pode declinar até $70 \%$, o que é atribuído à auto-toxicidade, à degradação e às pragas do solo; portanto, a rotação de culturas é essencial para que o manejo agrícola seja rentável (MCLEAN et al., 2002).

\subsection{Definição dos produtos}

O arroz é conhecido pelos tipos e subprodutos, conforme mostra a Figura 3. A seguir, serão dadas as definições dos mais comuns (MCLEAN et al., 2002; BASSINELLO et al., 2008):

Arroz em casca: pode ser o arroz verde recém-colhido da lavoura ou o arroz de armazenamento, que já passou pelo processo de secagem.

Arroz integral: arroz que, no processo de beneficiamento, foi retirada a casca do grão inteiro.
Arroz polido: arroz obtido através do descasque e polimento do grão integral, sendo a principal forma de consumo na maioria das regiões brasileiras.

Arroz parboilizado: o arroz é submetido, ainda em casca, a um processo hidrotérmico que provoca a gelatinização total ou parcial do amido, passando posteriormente pelo descasque e polimento. É possível encontrar arroz parboilizado na forma integral ou polido.

Arroz vermelho: pertence à mesma espécie do arroz cultivado, porém é considerado uma planta daninha; o acúmulo de tanino ou antocianina deixa o pericarpo com coloração avermelhada. Este tipo de arroz pode ser cultivado e consumido.

Arroz negro: de linhagem diferente do arroz comum, possui casca escura com acúmulo de antocianina no pericarpo, na película da semente e na fibra exterior do grão.

Quirera (arroz quebrado): arroz resultante do processamento, que se quebra em fragmentos pequenos. Pode ser usado em ração de animais, fabricação de cerveja, pasta de arroz, vinagre, biscoitos, macarrão, farinha e amido e serve como substrato para a fermentação alcoólica para obtenção de etanol.

Farinha: produto da moagem dos grãos de arroz previamente selecionados por intermédio de um moinho.

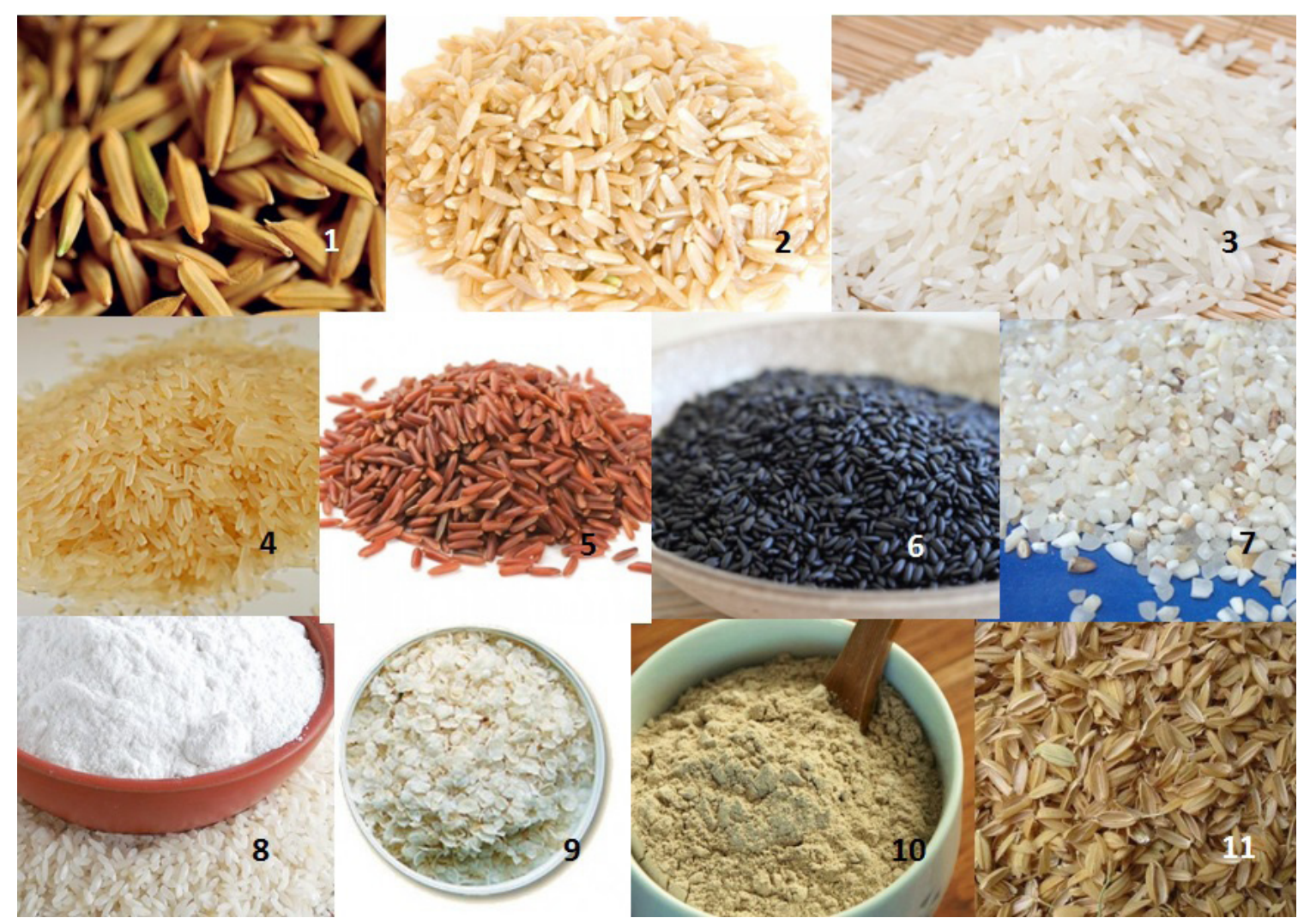

Figura 3. Tipos e sub produtos do arroz: 1. Arroz em casca; 2. Arroz integral; 3. Arroz polido; 4. Arroz parboilizado; 5. Arroz vermelho; 6. Arroz negro; 7. Quirera; 8. Farinha; 9. Floco; 10. Farelo; 11. Casca. 
Floco: resultado da extrusão dos grãos de arroz.

Farelo: é o subproduto do polimento do arroz e contém, em média, 20\% de lipídeos, 14\% de proteínas e bons teores de vitamina e fibras. É utilizado em ração de animais, extração de óleo comestível, produção de farinhas e concentrado proteico.

Casca: resultado do descasque, não tem aplicação alimentar.

\subsection{Processamento do arroz}

A fim de compreender melhor as etapas do processamento do arroz, uma breve explicação será dada, juntamente com o fluxograma apresentado na Figura 4. Em geral, no Brasil, a colheita do arroz é feita mecanicamente, através de colhedeiras próprias para este fim, as quais já separam, no campo, o grão de arroz com casca da planta (COOPERJA, 2016). Em seguida, este arroz é transportado por caminhões para os locais de processamento. $\mathrm{O}$ arroz é pesado diretamente do caminhão e encaminhado para o tombador e para as moegas, em que são realizadas a descarga e a coleta de amostras para a sua classificação. De cada amostra, são determinados o percentual de impurezas, a umidade, o rendimento e os defeitos. Do tombador, o arroz é transportado através de caracóis helicoidais e elevadores até um silo pulmão, no qual é feita a limpeza primária com uma peneira, para a retirada de impurezas maiores. Após a limpeza primária, o arroz é armazenado em silos secadores para a secagem. O processo de secagem é realizado até que o arroz atinja uma umidade de $13 \%$ a $14 \%$, para depois ser estocado em silos de armazenamento (COOPERJA, 2016).

Processamento do arroz parboilizado: para a produção do arroz parboilizado, o arroz que estava armazenado passa por uma limpeza secundária, em que o arroz é novamente peneirado para retirar as impurezas restantes, e em seguida é levado aos tanques de encharcamento. Neste tanque, o arroz é encharcado com água quente a uma temperatura em torno de $68^{\circ} \mathrm{C}$ a $72{ }^{\circ} \mathrm{C}$, por aproximadamente seis a sete horas. Após esse período, o arroz passa por uma estufa de $400{ }^{\circ} \mathrm{C}$ a $500{ }^{\circ} \mathrm{C}$ por um período de 2 a $3 \mathrm{~min}$. Após a estufa, o arroz segue para o secador, até a umidade baixar em torno de $12,5 \%$ a $13 \%$, a fim de evitar a proliferação

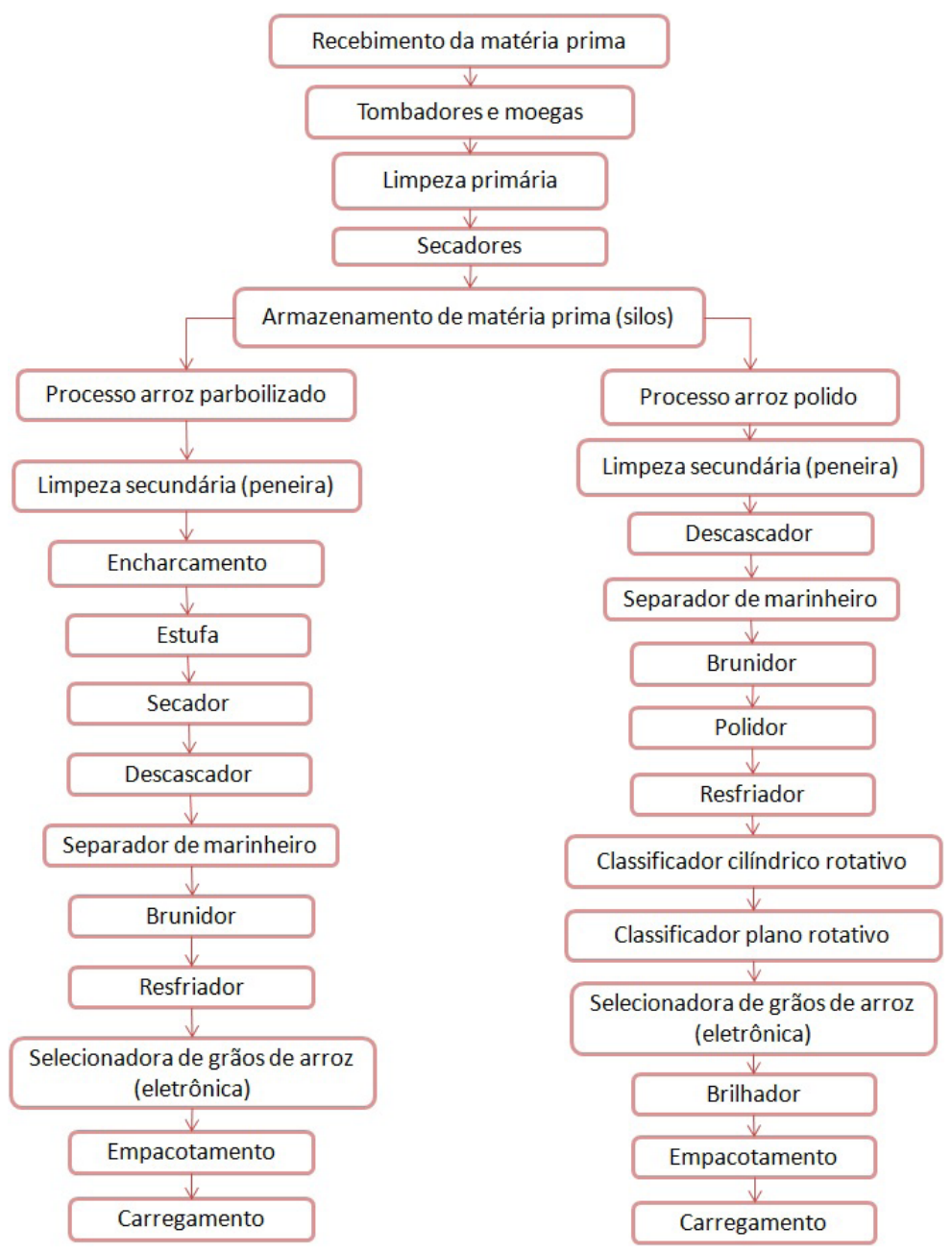

Figura 4. Fluxograma do processamento do arroz (COOPERJA, 2016). 
de fungos e insetos. Deste ponto, é feito o descasque, seguindo para o separador de marinheiros (grãos de arroz não descascados). Após essa separação, o arroz passa pelo brunidor, no qual é feito o polimento, extraindo-se o farelo e deixando a superfície lisa. O arroz é então levado ao resfriador, devido à elevação da temperatura no brunidor. Deste ponto, o arroz passa por uma seleção eletrônica para retirar os grãos considerados defeituosos. Finalmente, os grãos selecionados são empacotados e levados ao local de transporte. Todo o movimento deste processamento é feito em esteiras apropriadas.

Processamento do arroz polido: o arroz que estava armazenado no silo passa por uma limpeza secundária, em que o arroz é peneirado para retirar as impurezas; em seguida, é encaminhado para o descascador, o separador de marinheiros, o brunidor e o polidor, no qual ocorre o acabamento do grão com jato de água e a retirada total do farelo. Após esta etapa, o arroz segue para o resfriador, classificador cilíndrico rotativo, que serve para a retirada dos grãos rajados, as matérias-primas estranhas e as impurezas restantes, além de retirar a quirera (arroz quebrado). Deste ponto, o arroz passa para o classificador plano rotativo, que tem a função de separar a quirera que restou da etapa anterior. Na sequência, é feita a seleção eletrônica, passando em seguida para o brilhador, que adiciona talco e glicose no grão, a fim de deixar o grão com um aspecto brilhoso. Finalmente, os grãos são empacotados e levados ao local de transporte. Todo o movimento do processamento é conduzido por esteiras.

\section{Aflatoxinas}

Micotoxinas são metabólitos secundários produzidos por fungos filamentosos. Apresentam estruturas químicas distintas, além de baixo peso molecular, e podem causar doenças ou morte quando ingeridas por animais ou humanos. Os fatores relacionados à sua produção pelo fungo envolvem genótipo e fisiologia, caracterizando-o como produtor ou não, além de fatores extrínsecos, como umidade e temperatura, e fatores intrínsecos, como atividade de água e $\mathrm{pH}$. Dentre as micotoxinas encontradas no arroz, as aflatoxinas são as mais comuns. Quimicamente, as aflatoxinas são moléculas de di-hidrofuranos unidas a anéis cumarínicos e, assim, como outros compostos heterocíclicos, fluorescem sob luz ultravioleta, sendo distinguidas por suas propriedades fluorescentes (HUSSEIN; BRASEL, 2001). As quatro principais aflatoxinas são chamadas de $B_{1}, B_{2}, G_{1}$ e $G_{2}$, classificação baseada na coloração da fluorescência azul (blue) ou verde (green) emitida sob luz ultravioleta a $365 \mathrm{~nm}$.

As aflatoxinas são pouco solúveis em água, insolúveis em solventes apolares e solúveis em solventes moderadamente polares, como clorofórmio e metanol, e especialmente em dimetil sulfóxido (IARC, 2002).
São metabólitos extremamente tóxicos, sendo o análogo $B_{1}$ considerado o mais tóxico, classificado pela International Agency for Research on Cancer (IARC, 1993) como pertencente à classe 1, i.e. composto carcinogênico ao homem, sendo o fígado o principal órgão atingido após sua ingestão. A resolução RDC 07/2011 publicada pela ANVISA (BRASIL, 2011a) determina que o limite máximo tolerável de aflatoxinas em cereais não ultrapasse $5 \mu \mathrm{g} / \mathrm{kg}$.

A exposição às aflatoxinas pode causar uma intoxicação aguda ou crônica. Estima-se que $\mathrm{DL}_{50}$ para intoxicação aguda em humanos seja de 5 mg/kg (MOSS, 2002); entretanto, estes casos são raros. Em 2004, houve um surto de aflatoxicose aguda no Quênia, com 317 casos e 125 mortes, envolvendo milho contaminado, sendo que as amostras de milho apresentaram concentração média de 354,53 $\mu \mathrm{g} / \mathrm{kg}$ (AZZIZ-BAUMGARTNER et al., 2005). Por outro lado, a ocorrência de carcinoma hepatocelular devido à exposição crônica das aflatoxinas tem sido bem documentada, geralmente com uma maior ocorrência em áreas onde a infecção pelo vírus da hepatite B é endêmica ou em associação com fatores de risco (QIAN et al., 1994; WANG et al., 2001; CHEN et al., 2001; HENRY et al., 2002).

\subsection{Fungos produtores de aflatoxinas}

As aflatoxinas são produzidas principalmente por Aspergillus flavus, Aspergillus parasiticus e Aspergillus nomius (PITT; HOCKING, 2009). Outras espécies aflatoxigênicas menos comuns são: A. pseudotamarii, A. bombycis, A. toxicarius, A. parvisclerotigenus, A. arachidicola, A. minisclerotigenes, A. ochraceoroseus, A. rambelii, A. pseudonomius, A. pseudocaelatus, A. togoensis, A. mottae, A. sergii, A. transmontanensis, A. novoparasiticus, Emericella astellata e Emericella venezuelensis (ITO et al., 2001; PETERSON et al., 2001; MURAKAMI, 1971; PILDAIN et al., 2008; FRISVAD et al., 1999, 2004, 2005; VARGA et al., 2011; SOARES et al., 2012; GONÇALVES et al., 2012).

O gênero Aspergillus pertence à classe dos hifomicetos, que se reproduz assexuadamente, através de estruturas denominadas conídios, e que possui colônias que diferem na coloração e nas estruturas de frutificação. Apresenta formação de conidióforos com estipes grandes e largos, e vesícula geralmente esférica na extremidade (PITT; HOCKING, 2009). Na porção fértil da vesícula, ocorre a formação das fiálides, estruturas responsáveis pela produção de conídios (esporos mitóticos). O gênero pode ser classificado como monosseriado, quando apresenta apenas fiálides, e bisseriado, quando apresenta métula e fiálide. O tamanho, o arranjo e a coloração do conídio são características importantes para identificação das espécies (PITT; HOCKING, 2009).

Aspergillus flavus possui colônias caracteristicamente verdes amareladas e $50 \%$ das cepas de $A$. flavus isoladas produzem esclerócios pretos. Apresenta vesículas 
globosas a subglobosas e as fiálides nascem diretamente na vesícula ou na métula. Os conídios são globosos a subglobosos, verdes pálidos, finamente enrugados. Apresenta temperatura mínima de crescimento por volta de $12{ }^{\circ} \mathrm{C}$, máxima próxima de $48{ }^{\circ} \mathrm{C}$ e ótima entre $25^{\circ}$ e $42^{\circ} \mathrm{C}$. O pH ótimo para crescimento é de 7,5 e a atividade de água mínima para crescimento é próxima a 0,80 (PITT; HOCKING, 2009). As micotoxinas mais importantes produzidas por $A$. flavus são as aflatoxinas $B_{1}$ e $B_{2}$, sendo que alguns isolados também produzem ácido ciclopiazônico (KLICH; PITT, 1988).

Aspergillus parasiticus é mais restrito geograficamente, quando comparado ao A. flavus. Apresenta temperatura de crescimento entre $12{ }^{\circ} \mathrm{C}$ e $42^{\circ} \mathrm{C}$, com valor ótimo a $32^{\circ} \mathrm{C}$. A atividade de água mínima para crescimento é de 0,82 a $25^{\circ} \mathrm{C}, 0,81$ a $30^{\circ} \mathrm{C}$ e 0,80 a $37^{\circ} \mathrm{C}$. O crescimento pode ocorrer numa faixa de $\mathrm{pH}$ de 2,4 a 10 (PITT; HOCKING, 2009). A maioria das cepas é produtora de aflatoxinas $B_{1}, B_{2}, G_{1}$ e $\mathrm{G}_{2}$ (FRISVAD et al., 2007).

Aspergillus nomius é estritamente relacionado a $A$. flavus, pois, na ausência de esclerócios, as duas espécies são morfologicamente indistinguíveis. A maior diferença é que $A$. nomius produz aflatoxinas $B$ e $G$, e seu esclerócio tem forma de bala, não esférica como de A. flavus. A. nomius cresce com a atividade de água mínima de 0,83 a $25^{\circ} \mathrm{C}$ e $30{ }^{\circ} \mathrm{C}$, e 0,81 a $37^{\circ} \mathrm{C}$ (PITT; HOCKING, 2009).

Existe uma diferença na porcentagem de isolados capazes de produzir aflatoxinas dentro de uma mesma espécie, como também a quantidade e o tipo de aflatoxinas produzidas por cada espécie. Cerca da metade dos isolados de A. flavus é aflatoxigênica, enquanto que 100\% de A. parasiticus possui tal capacidade (KLICH; PITT, 1988). A temperatura e a atividade de água são fatores que, além de influenciar o crescimento de cepas aflatoxigênicas, têm papel importante na expressão dos genes responsáveis pela biossíntese de aflatoxinas, estimulando a produção ou não. Enquanto a condição para crescimento de $A$. flavus é de $10^{\circ} \mathrm{C}-12{ }^{\circ} \mathrm{C}$ a $43^{\circ} \mathrm{C}-48^{\circ} \mathrm{C}$ e atividade de água entre $\mathrm{a}_{\mathrm{w}}=0,78$ a $33^{\circ} \mathrm{C}$ e $\mathrm{a}_{\mathrm{w}}=0,84$ a $25^{\circ} \mathrm{C}$, a condição para a produção de aflatoxinas é de $13^{\circ} \mathrm{C}-37^{\circ} \mathrm{C}$ e $\mathrm{a}_{\mathrm{w}}$ acima de $0,82 \mathrm{com}$ ótima a $16{ }^{\circ} \mathrm{C}-31^{\circ} \mathrm{C}$ e a $a_{w} 0,95$ - 0,99 (PITT; HOCKING, 2009).

\section{Ocorrência de fungos, aflatoxinas e outras micotoxinas no arroz do Brasil e do mundo}

$O$ arroz pode ser infectado por fungos antes da colheita, como Fusarium spp., e após a colheita, durante as fases de secagem ou armazenamento, por fungos como Aspergillus spp. e Penicillium spp. (PITT; HOCKING, 2009), que podem ser produtores de micotoxinas.

Dentre as micotoxinas que já foram encontradas no arroz, destacam-se as aflatoxinas (AFs), Ocratoxina A (OTA), Desoxinivalenol (DON), Zearalenona (ZON) e
Fumonisina (FUM), que podem ocorrer conjuntamente (ALMEIDA et al., 2012).

Almeida et al. (2012), no Brasil, analisaram 230 amostras de arroz e frações processadas, como: quebrados, farelo de arroz e casca de arroz, avaliando a ocorrência das seguintes micotoxinas: AFs, ZON, OTA, DON e citreoviridina (CTV). Neste trabalho, as amostras de arroz estavam contaminadas com AFs totais (58,7\%), OTA (40\%), ZON (45,2\%), DON (8,3\%) e CTV (22,5\%). A maioria das amostras não continha DON, embora uma amostra tenha apresentado níveis de $244 \mu \mathrm{g} / \mathrm{kg}$. Os maiores níveis de contaminação foram encontrados nos subprodutos de arroz, como casca e farelo, havendo co-ocorrência de: AFs e ZON em $17 \%$, AFs e OTA em $24,2 \%$, AFs e CTV em $6,2 \%$, OTA e CTV em $4,6 \%$, e ZON e CTV em 3,1\%. Nesse trabalho, Almeida et al. (2012) não analisaram a micobiota e, assim, os fungos produtores destas toxinas não foram conhecidos. Gomes et al. (2015) analisaram 130 amostras de arroz em casca do campo da Região Sul do Brasil e obtiveram 89 isolados, identificando quatro espécies de Fusarium spp.: F. asiaticum, F. graminearum, F. cortaderiae e F. meridionale. Em seguida, realizaram o teste de produção de micotoxinas in vitro, utilizando arroz polido como substrato, e observaram a produção de NIV pelos isolados de $F$. asiaticum, a produção de 15-acetil(A)desoxinivalenol(DON) e uma menor quantidade de 3-acetil(A)desoxinivalenol(DON) pelos isolados de F. graminearum. Os isolados F. cortaderiae e F. meridionale não apresentaram níveis detectáveis de tricotecenos no substrato de arroz.

Estudos sobre a exposição às aflatoxinas pelo consumo de alimentos têm sido realizados em algumas partes do mundo. Kuiper-Goodman (1998) recomenda que a ingestão diária máxima tolerável (IDMT) de aflatoxinas não deve ultrapassar 1,0 ng/kg de peso corpóreo/dia para adultos e crianças sem hepatite $B$, e $0,4 \mathrm{ng} / \mathrm{kg}$ de peso corpóreo/dia para adultos com hepatite B,

$\mathrm{Na}$ Coreia do Sul, Park et al. (2004) investigaram a exposição diária à aflatoxina $\mathrm{B}_{1}$ através do consumo de alimentos e concluiu que o arroz foi o maior contribuidor para a ingestão desta toxina. Neste estudo, das 88 amostras comerciais de arroz polido analisadas, cinco (6\%) amostras apresentaram uma média de $4,8 \mu \mathrm{g} / \mathrm{kg}$ de $\mathrm{AFB}_{1}$. A estimativa de ingestão diária de aflatoxinas pelos coreanos foi de 1,19 a 5,79 ng/kg de peso corpóreo/dia, o que excede a ingestão máxima diária tolerável (IDMT), causando, dessa forma, uma preocupação na saúde dessa população (PARK et al., 2004).

Posteriormente, Park et al. (2005) estudaram a presença de várias micotoxinas, como: fumonisinas, ocratoxina $A$, desoxinivalenol, nivalenol (NIV) e zearalenona, além da micobiota do arroz cultivado em sistema de rotação de cultura com cevada. Esses autores verificaram que 45\% das amostras apresentaram infecção fúngica, sendo 17\% 
com A. flavus; entretanto, apenas um dos 15 isolados foi produtor de AFB. A quantidade de amostras contaminadas com FUM B $B_{1}$ OTA, DON, NIV e ZON foi baixa, sendo o percentual de 2,27\%, 9,09\%, 3,41\%, 5,68\% e 3,41\%, com média de 54,4 $\mu \mathrm{g} / \mathrm{kg}, 3,9 \mu \mathrm{g} / \mathrm{kg}, 139 \mu \mathrm{g} / \mathrm{kg}, 352 \mu \mathrm{g} / \mathrm{kg}$ e $38,5 \mu \mathrm{g} / \mathrm{kg}$, respectivamente.

Num estudo realizado em Uganda, por Taligoola et al. (2011), sobre a micobiota e presença de aflatoxinas no arroz polido importado do Paquistão, durante o armazenamento de 270 dias, foi observada uma alta incidência de fungos xerofílicos, como Eurotium amstelodami, E. chevalieri, E. rubrum e Aspergillus candidus. A. flavus foi encontrado em apenas duas amostras, nos oito períodos de armazenamento. Oito das dez amostras apresentaram presença de aflatoxinas, sendo que uma estava acima do limite permitido em Uganda, que é de $20 \mu \mathrm{g} / \mathrm{kg}$; numa faixa de $20-50 \mu \mathrm{g} / \mathrm{kg}$, duas estavam no intervalo de $10 \mu \mathrm{g} / \mathrm{kg}$ a $20 \mu \mathrm{g} / \mathrm{kg}$ e cinco, no intervalo de ND a $10 \mu \mathrm{g} / \mathrm{kg}$. Considerando-se o limite máximo permitido no Brasil, a maior parte destas amostras não seria aceita no mercado brasileiro.

Na Coreia do Sul, devido à busca por uma alimentação mais saudável, o consumo do arroz polido tem decrescido com o aumento do consumo do arroz integral. Ok et al. (2014) analisaram 80 amostras de arroz recém-colhido de diferentes regiões do país. Os gêneros de fungos mais frequentes foram: Fusarium spp., Penicillium spp., Phoma spp., Alternaria spp., Myrothecium spp. e Cladosporium spp. Foram isolados também $A$. flavus e $A$. clavatus, não produtores de toxinas. $O$ arroz polido não apresentou aflatoxinas, enquanto que $7,5 \%$ das amostras de arroz integral apresentaram aflatoxinas no intervalo de 0,7 $\mu \mathrm{g} / \mathrm{kg}$ a 2,7 $\mu \mathrm{g} / \mathrm{kg}$. Provavelmente, o polimento do arroz poderia decrescer a concentração de aflatoxinas; contudo, este fato não foi investigado pelos autores.

No Iraque, o arroz é importado de vários países, como Estados Unidos, Uruguai, Argentina, Brasil e Índia, por não se suprir a demanda interna. Ali et al. (2016) analisaram a micobiota de 50 amostras de três províncias do Iraque e observaram que os gêneros mais comuns foram: Bipolaris spicifera, Curvularia lunata, Fusarium spp., Exserohillum rostratum, Nigrospora oryzae, Thanatephorus cucumeris e Alternaria spp. Nesse trabalho, não foi realizada nenhuma pesquisa das micotoxinas que poderiam estar presentes no arroz.

Um estudo interlaboratorial realizado na Índia, com 581 amostras de arroz parboilizado, detectou $\mathrm{AFB}_{1} \mathrm{em}$ $38 \%$ destas, com concentração $\geq 5 \mu \mathrm{g} / \mathrm{kg}$, e 17\% com contaminação acima de $30 \mu \mathrm{g} / \mathrm{kg}$, sendo que o limite máximo para $A F B$, permitido na Índia é de $30 \mu \mathrm{g} / \mathrm{kg}$ (TOTEJA et al., 2006).

Em um estudo realizado na Índia, por Reddy et al. (2009a), foram analisadas 1.200 amostras de arroz, sendo uma parte em casca e outra de arroz polido, quanto à infecção por Aspergillus spp. e presença de AFB . Todas as amostras de arroz em casca estavam infectadas com A. flavus, e 67,7\% apresentaram $A_{F} B_{1}$ de 0,1 $\mu \mathrm{g} / \mathrm{kg}$ a $308 \mu \mathrm{g} / \mathrm{kg}$. Note-se que, dentre estas amostras, 2\% apresentaram contaminação maior que o limite permitido $(30 \mu \mathrm{g} / \mathrm{kg})$. As amostras de arroz polido apresentaram $\mathrm{AFB}_{1}$ no intervalo de 0,5 $\mu \mathrm{g} / \mathrm{kg}$ a 3,5 $\mu \mathrm{g} / \mathrm{kg}$.

Em Cleveland-EUA, foram analisadas amostras de arroz e suas frações durante o processamento, e estas apresentaram níveis muito altos de aflatoxina, numa média de $114 \mu \mathrm{g} / \mathrm{kg}$ de arroz com casca, $39 \mu \mathrm{g} / \mathrm{kg}$ na casca, $158 \mu \mathrm{g} / \mathrm{kg}$ no arroz integral, $357 \mu \mathrm{g} / \mathrm{kg}$ no farelo e $56 \mu \mathrm{g} / \mathrm{kg}$ no arroz polido (TRUCKSESS et al., 2011).

Nas Filipinas, amostras de arroz integral e polido tiveram uma maior incidência de Aspergillus section Flavi do que o arroz com casca, porém o arroz com casca apresentou maior taxa de fungos produtores de aflatoxinas. O maior nível de aflatoxinas foi encontrado no farelo $(9,97 \mu \mathrm{g} / \mathrm{kg})$, seguido da casca de arroz $(5,02 \mu \mathrm{g} / \mathrm{kg})$ e do arroz integral (4,32 $\mathrm{gg} / \mathrm{kg}$ ) (SALES; YOSHIZAWA, 2005).

Makun et al. (2011), na Nigéria, analisaram 21 amostras de arroz, sendo dez do campo, seis do armazenamento e cinco comerciais. Todas as amostras apresentaram níveis de aflatoxinas acima dos limites aceitáveis de 77 países que regulamentam aflatoxinas, incluindo a União Europeia $(10 \mu \mathrm{g} / \mathrm{kg})$, sendo a média encontrada de aflatoxinas totais de $82,5 \mu \mathrm{g} / \mathrm{kg}$ (no intervalo de 27,7 $\mu \mathrm{g} / \mathrm{kg}$ e 371,9 $\mu \mathrm{g} / \mathrm{kg}$ ). Estas amostras também não seriam aceitas no Brasil.

O limite máximo de aflatoxinas no arroz, estabelecido pelo Turkish Food Codex (TFC) (AYDIN et al., 2011), é de $4 \mu \mathrm{g} / \mathrm{kg}$. Um estudo realizado por Aydin et al. (2011) revelou que $56 \%$ das 100 amostras de arroz produzido na Turquia estavam contaminadas com aflatoxinas, num intervalo de $0,05 \mu \mathrm{g} / \mathrm{kg}$ a $21,4 \mu \mathrm{g} / \mathrm{kg}$, sendo que $32 \%$ estavam acima do limite máximo estabelecido pelo TFC.

A ocorrência de aflatoxinas em arroz consumido por militares do exército brasileiro foi analisada por Silva et al. (2008) em Curitiba, utilizando duas técnicas de detecção: (i) cromatografia de camada delgada (CCD), com limite de quantificação de $3 \mu \mathrm{g} / \mathrm{kg}$, e (ii) cromatografia líquida de alta eficiência (CLAE), com limite de quantificação de $0,5 \mu \mathrm{g} / \mathrm{kg}$. Pela técnica de CCD, nenhuma das 30 amostras apresentou aflatoxinas e, por CLAE, seis das 26 amostras apresentaram aflatoxinas no intervalo de 0,54 $\mu \mathrm{g} / \mathrm{kg}$ a $2,04 \mu \mathrm{g} / \mathrm{kg}$. Já um estudo realizado na Região Sul do Brasil, com 32 lotes de arroz parboilizado, revelou que três amostras estavam contaminadas por aflatoxinas no intervalo de 11,53 $\mu \mathrm{g} / \mathrm{kg}$ a $74 \mu \mathrm{g} / \mathrm{kg}$ (DORS et al., 2011).

Em 2010, Carvalho et al. (2010) avaliaram a incidência de fungos toxigênicos e aflatoxinas no arroz comercializado em Belo Horizonte e algumas cidades do sul de Minas Gerais, sendo 48 amostras de arroz polido, três de arroz parboilizado, sete de arroz integral e duas de arroz orgânico. 
O maior índice de infecção fúngica no arroz foi de 100\%, 42\%, 32\% e 13\%, nas amostras de arroz orgânico, polido, integral e parboilizado, respectivamente. Foram isolados 184 fungos, dentre os quais: $A$. candidus, $A$. carbonarius, A. flavus, A. niger, A. tamarii, Alternaria alternata, Eurotium spp., Fusarium spp., P. citrinum, P. glabrum, Rhizopus spp. e Trichoderma spp. Dos 48 isolados dos Aspergillus section Flavi, 17 foram identificados como A. parasiticus, sendo 14 produtores de AFB e AFG, e 31 como A. flavus, sendo apenas oito produtores de AFB. Apenas uma das 36 amostras apresentou aflatoxinas com nível de 1,2 $\mu \mathrm{g} / \mathrm{kg}$.

Beber-Rodrigues e Scussel (2013) analisaram a micobiota e a presença de micotoxinas (aflatoxinas, ocratoxina A e zearalenona) em quatro cultivares diferentes de arroz em casca, sendo dez amostras de cada cultivar, recémcolhidas e provenientes da cidade de Massaranduba-SC. Os autores investigaram a relação do tempo entre a colheita e a recepção na indústria, concluindo que não houve influência significativa do tempo de espera dos caminhões na umidade do arroz, na atividade de água e na infecção fúngica. Os gêneros que apresentaram maior incidência foram Penicillium spp. e Aspergillus spp., e não foi detectada a presença das micotoxinas estudadas (aflatoxinas, ocratoxina A e zearalenona).

Uma das preocupações da presença de aflatoxinas no arroz dá-se pela presença das mesmas nos subprodutos, como farelo, farinha e seus derivados. Jayaraman e Kalyanasundaram (2009) detectaram AFB, no óleo do farelo de arroz em $75 \%$ das amostras de óleo cru, que apresentaram uma média de $618 \mu \mathrm{g} / \mathrm{kg}$ (236 $\mu \mathrm{g} / \mathrm{kg}$ a $956 \mu \mathrm{g} / \mathrm{kg}) ; 30 \%$ das amostras de óleo refinado apresentaram uma média de $20 \mu \mathrm{g} / \mathrm{kg}$ (traço a $28 \mu \mathrm{g} / \mathrm{kg}$ ) e 66,7\% das amostras de de-oiled (óleo com menos gordura e alta quantidade de proteínas) apresentaram uma média de $33 \mu \mathrm{g} / \mathrm{kg}(7 \mu \mathrm{g} / \mathrm{kg}$ a $114 \mathrm{\mu g} / \mathrm{kg}$ ). Quanto à presença de $A$. flavus produtores de aflatoxinas, 20 dos 30 e 9 dos 15 isolados das amostras de de-oiled e óleo refinado, respectivamente, foram produtores de aflatoxinas. Nesse trabalho, os autores sugerem que o período de tempo entre o descascamento, o processamento, a comercialização, o transporte e o armazenamento pode favorecer o desenvolvimento de fungos toxigênicos e o início da produção de toxinas. Nesse estudo, foi verificado que a alta incidência de aflatoxinas no óleo cru foi reduzida durante o processo de refinamento, mas 30\% das demais amostras de óleo ainda apresentaram nível acima de $30 \mu \mathrm{g} / \mathrm{kg}$ (nível máximo tolerado na Índia).

$\mathrm{Na}$ Tabela 1, podem ser visualizados os dados disponíveis na literatura sobre a ocorrência de aflatoxinas totais em arroz e produtos de arroz.

\section{Métodos de redução de aflatoxinas no arroz}

No sistema de arroz irrigado, este é cultivado sob as águas nos primeiros estágios do desenvolvimento; assim, os níveis de $A$. flavus dos solos são baixos, com baixa contaminação nos grãos maduros e, consequentemente, no produto final. Entretanto, se os grãos forem colhidos úmidos e se houver demora na secagem, poderá haver um aumento na infecção por A. flavus (PITT et al., 2013). Por outro lado, no sistema sequeiro, o arroz é cultivado em solos com umidade moderada, o que pode talvez favorecer o desenvolvimento de $A$. flavus, devido à sua característica mais xerofílica, quando comparado com outros fungos que podem acometer a cultura do arroz. Contudo, faltam estudos que mostrem este fato.

A Figura 5 mostra a aplicação do conceito de objetivo da segurança do alimento (FSO - Food Safety Objective) para grãos, como trigo, cevada e arroz. O FSO (PITT et al., 2013) estabelece, de forma flexível, metas que devem ser atingidas na cadeia produtiva para obter uma frequência ou concentração máxima de um perigo no alimento no momento do consumo. No caso do arroz cru, o limite de aflatoxinas permitido pela RDC 07/11 (BRASIL, 2011b) é de $5 \mu \mathrm{g} / \mathrm{kg}$, embora não exista uma concentração para o arroz cozido, este limite pode ser considerado o FSO. Os pontos críticos para o aumento da concentração de aflatoxinas se encontram principalmente na secagem e no armazenamento, fases nas quais os fungos produtores de aflatoxinas podem se desenvolver, se houver condições favoráveis.

Alguns estudos mostraram que é possível reduzir os níveis de aflatoxinas no arroz durante o beneficiamento e também durante o cozimento, no momento do consumo.

Nas Filipinas, foi observada uma redução de $78 \%$ de aflatoxinas no processo de polimento do arroz integral para o arroz polido e uma redução de $38 \%$ do polimento comum para o arroz com maior polimento (SALES; YOSHIZAWA, 2005).

O tipo de secagem utilizado também influencia na redução de aflatoxinas no arroz. Prietto et al. (2015) analisaram amostras de arroz e suas frações (farelo, endosperma e casca) armazenadas, provenientes de secagem intermitente e secagem estacionária. Concluíram que a secagem intermitente é mais apropriada para a armazenagem por longos períodos, porque houve menos produção de aflatoxinas.

Um estudo realizado por Park e Kim (2006) concluiu que houve uma redução de $31 \%$ a $36 \%$ de $A F B$, no cozimento comum (panela elétrica) e uma redução de $78 \%$ a $83 \%$ no cozimento com pressão. Hussain e Luttfullah (2009) observaram uma redução de $84 \%$ de AFB, no cozimento comum, $87,5 \%$ com excesso de água e $72,5 \%$ no cozimento por micro-ondas. Sani et al. 
Fungos e aflatoxinas no arroz: ocorrência e significado na saúde do consumidor

Katsurayama, A. M.; Taniwaki, M. H.

Tabela 1. Dados sobre a ocorrência de aflatoxinas totais em arroz e produtos de arroz

\begin{tabular}{|c|c|c|c|c|c|c|}
\hline $\begin{array}{l}\text { Produto } \\
\text { de arroz }\end{array}$ & $\begin{array}{c}\mathrm{N}^{\circ} \\
\text { amostras }\end{array}$ & $\begin{array}{c}\text { Incidência de } \\
\qquad \text { AFT } \\
(\%)\end{array}$ & $\begin{array}{l}\text { Mínimo-Máximo } \\
\qquad(\mu g / k g)\end{array}$ & Método & País & Referência \\
\hline Arroz polido & 166 & 40 & ND-176,31 & CLAE & Brasil & Almeida et al. (2012) \\
\hline Arroz em casca & 27 & 97 & ND-31,72 & CLAE & Brasil & Almeida et al. (2012) \\
\hline Farelo & 19 & 89 & ND-207,04 & CLAE & Brasil & Almeida et al. (2012) \\
\hline Quirera & 18 & 94 & ND-19,42 & CLAE & Brasil & Almeida et al. (2012) \\
\hline Arroz polido & 88 & 6 & $2,1-7,7$ & CLAE & Coreia & Park et al. (2004) \\
\hline Arroz polido & 10 & 80 & ND-50 & CLAE & Uganda & Taligoola et al. (2011) \\
\hline Arroz polido & 80 & 0 & ND & CLAE & $\begin{array}{l}\text { Coreia do } \\
\quad \text { Sul }\end{array}$ & Ok et al. (2014) \\
\hline Arroz integral & 80 & 7,5 & ND-2,7 & CLAE & $\begin{array}{l}\text { Coreia do } \\
\quad \text { Sul }\end{array}$ & Ok et al. (2014) \\
\hline Arroz parboilizado & 1511 & 38 & $<5->30$ & CLAE & Índia & Toteja et al. (2006) \\
\hline Arroz integral & 9 & 100 & $0,025-8,7$ & CLAE & Filipinas & Sales e Yoshizawa (2005) \\
\hline Arroz polido & 68 & 94 & ND - 8,7 & CLAE & Filipinas & Sales e Yoshizawa (2005) \\
\hline Arroz em casca & 16 & 100 & $27,7-371,9$ & CLAE & Nigéria & Makun et al. (2011) \\
\hline Arroz polido & 5 & 100 & $27,7-371,10$ & CLAE & Nigéria & Makun et al. (2011) \\
\hline Arroz polido & 100 & 56 & $<0,05->21,4$ & ELISA & Turquia & Aydin et al. (2011) \\
\hline Arroz parboilizado & 32 & 9 & ND-74 & CCD & Brasil & Dors et al. (2011) \\
\hline Arroz polido & 26 & 23 & ND-2,04 & $\begin{array}{l}\text { CCD/ } \\
\text { CLAE }\end{array}$ & Brasil & Silva et al. (2008) \\
\hline Arroz polido & 36 & 2 & ND-1,2 & CLAE & Brasil & Carvalho et al. (2010) \\
\hline $\begin{array}{l}\text { Óleo de farelo de } \\
\text { arroz cru }\end{array}$ & 20 & 75 & $236-956$ & CCD & Índia & $\begin{array}{c}\text { Jayaraman e Kalyanasundaram } \\
\text { (2009) }\end{array}$ \\
\hline $\begin{array}{l}\text { Óleo de farelo de } \\
\text { arroz refinado }\end{array}$ & 20 & 30 & traço-28 & CCD & Índia & $\begin{array}{c}\text { Jayaraman e Kalyanasundaram } \\
\text { (2009) }\end{array}$ \\
\hline $\begin{array}{l}\text { Óleo de farelo de } \\
\text { arroz (de-oiled) }\end{array}$ & 30 & 66,7 & $7-114$ & CCD & Índia & $\begin{array}{c}\text { Jayaraman e Kalyanasundaram } \\
\text { (2009) }\end{array}$ \\
\hline Arroz em casca & 675 & 70,7 & $0,1-308$ & ELISA & Índia & Reddy et al. (2009a) \\
\hline Arroz polido & 525 & 64,1 & $0,5-3,5$ & ELISA & Índia & Reddy et al. (2009a) \\
\hline Arroz em casca & 40 & 0 & ND & CCD & Brasil & Beber-Rodrigues e Scussel (2013) \\
\hline
\end{tabular}

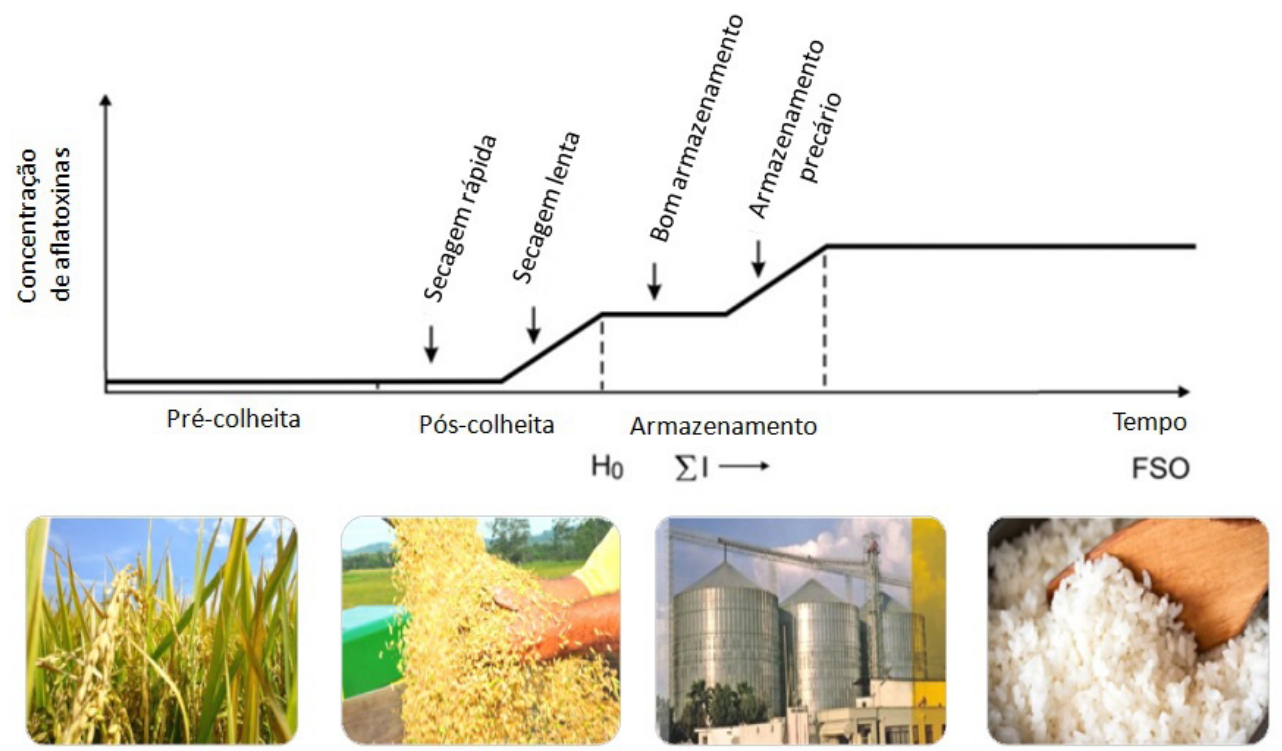

Figura 5. Formação de aflatoxinas durante a cadeia produtiva de pequenos grãos (PITT et al., 2013). 
(2012) observaram uma redução de $24,8 \%$ de $A F B$, no cozimento com panela elétrica e uma redução de 17,5\% no cozimento local, em fogão a gás.

Além do polimento e cozimento, há estudos de biocontrole sobre o crescimento de $A$. flavus e a produção de aflatoxina $B_{1}\left(A_{F B}\right)$ nos grãos de arroz. Na Índia, Reddy et al. (2009b) realizaram um estudo com extratos de plantas e outros agentes de biocontrole, verificando uma inibição do crescimento de $A$. flavus e da produção de $\mathrm{AFB}_{1}$. Nesse estudo, Syzigium aromaticum (cravo-da-índia), na concentração de $5 \mathrm{~g} / \mathrm{kg}$, foi capaz de inibir completamente o crescimento e a produção de $\mathrm{AFB}_{1}$. Curcuma longa (cúrcuma), Allium sativum (alho) e Ocimum sanctum (tulsi), na mesma concentração, inibiram cerca de $65 \%$ a $78 \%$ do crescimento de $A$. flavus e cerca de $72,2 \%$ a $85,7 \%$ da produção de $A F B_{1}$. Dentre os microrganismos estudados, Rhodococcus erythropolis, na concentração de $25 \mathrm{~mL} / \mathrm{kg}$, inibiu completamente o crescimento e a produção de $\mathrm{AFB}_{1}$. Pseudomonas fluorescens, Trichoderma virens e Bacillus subtilis, na concentração de $200 \mathrm{~mL} / \mathrm{kg}$, apresentaram $93 \%, 80 \%$ e $68 \%$ de redução do crescimento de A. flavus e $83,7 \%, 72,2 \%$ e $58 \%$ de redução de $\mathrm{AFB}_{1}$, respectivamente (REDDY et al., 2009b).

O uso de fungicidas triazóis nas plantações de arroz indicou uma redução de aflatoxina $B_{1}$ e outras micotoxinas como DON, zearalenona e ocratoxina A (DORS et al., 2013). Nesse estudo, os autores (DORS et al., 2013) concluíram que estes fungicidas podem inibir o desenvolvimento de fungos toxigênicos encontrados nos campos.

\section{Conclusão}

O arroz faz parte da alimentação diária de grande parte da população brasileira e mundial. Foi visto, nesta revisão, que os estudos realizados em diversos países, incluindo o Brasil, mostraram a presença de aflatoxinas em amostras de arroz comercial destinado ao consumo humano. Contudo, os trabalhos têm mostrado que ocorre uma redução desta toxina durante o cozimento do arroz, o que pode diminuir o risco, dependendo da concentração inicial. Mais estudos são necessários para verificar a presença de aflatoxinas e outras toxinas no arroz brasileiro, e as respectivas formas de prevenção e controle.

\section{Referências}

ALI, H. Z.; ABOUD, H. M.; DHEYAB, N. S.; ABDULQADER, A.; MOHAMMED, A. S.; SAOOD, H. M.; SALMAN, S. D. Detection and identification of mycobiota associated with rice in three districts of Iraq. International Journal of Phytopathology, Rawalpindi, v. 5, n. 1, p. 11-27, 2016.

ALMEIDA, M. I.; ALMEIDA, N. G.; CARVALHO, K. L.; GONÇALVES, G. A.; SILVA, C. N.; SANTOS, E. A.; GARCIA, J. C.; VARGAS, E. A. Co-occurrence of aflatoxins $B, B, G$ and $G$, ochratoxin $A$, zearalenone, deoxynivalenol, and citreoviridin in rice in Brazil.
Food Additives \& Contaminants. Part A, Chemistry, Analysis, Control, Exposure \& Risk Assessment, Abingdon, v. 29, n. 4, p. 694-703, 2012. PMid:22316345. http://dx.doi.org/10.1080/1 9440049.2011.651750.

AYDIN, A.; AKSU, H.; GUNSEN, U. Mycotoxin levels and incidence of mould in Turkish rice. Environmental Monitoring and Assessment, Dordrecht, v. 1-4, n. 178, p. 271-280, 2011. PMid:20824330. http://dx.doi.org/10.1007/s10661-010-1688-9.

AZZIZ-BAUMGARTNER, E.; LINDBLADE, K.; GIESEKER, K.; ROGERS, H. S.; KIESZAK, S.; NJAPAU, H.; SCHLEICHER, R.; MCCOY, L. F.; MISORE, A.; DECOCK, K.; RUBIN, C.; SLUTSKER, L. Case-control study of an acute aflatoxicosis outbreak, Kenya, 2004. Environmental Health Perspectives, Research Triangle Park, v. 113, n. 12, p. 1779-1783, 2005. PMid:16330363. http:// dx.doi.org/10.1289/ehp.8384

BASSINELLO, P. Z.; GARCIA, J. S.; SOARES, L. A.; KOAKUZU, S. N.; MOURA NETO, F. P.; FERREIRA, R. A.; MENDONÇA, J. A.; SANTIAGO, C. M.; RANGEL, P. H. N. Arroz preto: nova opção culinária para o Brasil. Santo Antônio do Goiás: EMBRAPA, 2008. (Comunicado Técnico, 147).

BEBER-RODRIGUES, M.; SCUSSEL, V. M. Mycoflora and mycotoxicological quality of four freshly harvested paddy rice cultivars and relation with harvest to industry reception timing. Rice Science, Hangzhou, v. 20, n. 4, p. 303-308, 2013. http:// dx.doi.org/10.1016/S1672-6308(13)60151-1.

BRASIL. Ministério da Agricultura, Pecuária e Abastecimento. Arroz. Brasília, 2009. Disponível em: <www.agricultura.gov.br/ vegetal/culturas/arroz>. Acesso em: 28 dez. 2016.

BRASIL. Ministério da Saúde. Agência Nacional de Vigilância Sanitária. Resolução n 7, de 18 de fevereiro de 2011. Dispõe sobre limites máximos tolerados (LMT) para micotoxinas em alimentos. Diário Oficial [da] República Federativa do Brasil, Brasília, DF, 22 fev. 2011 a. Seção 1, p. 72.

BRASIL. Ministério da Saúde. Agência Nacional de Vigilância Sanitária. Resolução de Diretoria Colegiada - RDC nº7, de 18 de fevereiro de 2011. Diário Oficial [da] República Federativa do Brasil, Brasília, DF, 22 fev. 2011b, Seção 1, p. 72. Disponível em: <http://portal.anvisa.gov.br/documents/10181/2968262/ RDC_07_2011_COMP.pdf/afe3f054-bc99-4e27-85c4-780b92e2b966>. Acesso em: 28 dez. 2016.

CARVALHO, R. A.; BATISTA, L. R.; PRADO, G.; DE OLIVEIRA, B. R.; SILVA, D. M. Incidência de fungos toxigênicos e aflatoxinas em arroz. Ciência e Agrotecnologia, Lavras, v. 34, n. 4, p. 946-952, 2010. http://dx.doi.org/10.1590/S1413-70542010000400021.

CHEN, S. Y.; CHEN, C. J.; CHOU, S. R.; HSIEH, L. L.; WANG, L. Y.; TSAI, W. Y.; AHSAN, H.; SANTELLA, R. M. Association of aflatoxin $B(1)$-albumin adduct levels with hepatitis $B$ surface antigen status among adolescents in Taiwan. Cancer Epidemiology, Biomarkers \& Prevention, Philadelphia, v. 10, n. 11, p. 12231226, 2001. PMid:11700273. 
Fungos e aflatoxinas no arroz: ocorrência e significado na saúde do consumidor

Katsurayama, A. M.; Taniwaki, M. H.

COMPANHIA NACIONAL DE ABASTECIMENTO - CONAB. Monitoramento agrícola. Acompanhamento da Safra Brasileira de Grãos, Brasília, v. 3, n. 9, p. 43-62, 2016.

COOPERATIVA AGROINDUSTRIAL - COOPERJA. Produção de arroz. Jacinto Machado, 2016. Disponível em: <www.cooperja. com.br/produtos/producaodearroz.pdf>. Acesso em: 23 dez. 2016.

DORS, G. C.; BIERHALS, V. S.; BADIALE-FURLONG, E. Parboiled rice: chemical composition and the occurrence of mycotoxins. Ciência e Tecnologia de Alimentos, Campinas, v. 31, n. 1, p. 172-177, 2011. http://dx.doi.org/10.1590/S0101-20612011000100025.

DORS, G. C.; CALDAS, S. S.; HACKBART, H. C. S.; PRIMEL, E. G.; FAGUNDES, C. A. A.; BADIALE-FURLONG, E. Fungicides and the effects of mycotoxins on milling fractions of irrigated rice. Journal of Agricultural and Food Chemistry, Washington, v. 61, n. 8, p. 1985-1990, 2013. PMid:23339481. http://dx.doi. org/10.1021/jf305144t.

FOOD AND AGRICULTURE ORGANIZATION OF THE UNITED NATIONS - FAO. Food outlook: biannual report on global food markets. Rome, 2016. 139 p.

FREDLUND, E.; THIM, A. M.; GIDLUND, A.; BROSTEDT, S.; NYBERG, M.; OLSEN, M. Moulds and mycotoxins in rice from the Swedish retail market. Food Additives and Contaminants, London, v. 26, n. 4, p. 527-533, 2009. PMid:19680928. http:// dx.doi.org/10.1080/02652030802562912.

FRISVAD, J. C.; HOUBRAKEN, J.; SAMSON, R. A. Aspergillus species and aflatoxin production: a reappraisal. In: TUIJTELAARS, A. C. J.; SAMSON, R. A.; ROMBOUTS, F. M.; NOTERMANS, S. (Ed.). Food microbiology: two novel aflatoxin producing Aspergillus species. Food safety into the next millennium. Zeist: Foundation Food Micro, 1999. v. 99, p. 125-126.

FRISVAD, J. C.; SAMSON, R. A.; SMEDSGAARD, J. Emericella astellata, a new producer of aflatoxin $B, B$ and sterigmatocystin. Letters in Applied Microbiology, Oxford, v. 38, n. 5, p. 440-445, 2004. PMid:15059218. http://dx.doi.org/10.1111/j.1472765X.2004.01520.x

FRISVAD, J. C.; SKOUBOE, P.; SAMSON, R. A. Taxonomic comparison of three different groups of aflatoxin producers and a new efficient producer of aflatoxin $B_{1}$, sterigmatocystin, and 3-O-methylsterygmatocystin, Aspergillus rambelly sp. Systematic and Applied Microbiology, New York, v. 28, n. 5, p. 442-453, 2005. PMid:16094871. http://dx.doi.org/10.1016/j. syapm.2005.02.012.

FRISVAD, J. C.; THRANE, U.; SAMSON, R. A. Mycotoxin producers. In: DIJKSTERHUIS, J.; SAMSON, R. A. Food mycology: a multifaceted approach to fungi and food. New York: CRC Press, 2007. p. 411

GOMES, L. B.; WARD, T. J.; BADIALE-FURLONG, E.; DEL PONTE, E. M. Species composition, toxigenic potential and pathogenicity of Fusarium graminearum species complex isolates from southern
Brazilian rice. Plant Pathology, New York, v. 64, n. 4, p. 980-987, 2015. http://dx.doi.org/10.1111/ppa.12332

GONÇALVES, S. S.; STCHIGEL, A. M.; CANO, J. F.; GODOYMARTINEZ, P. C.; COLOMBO, A. L.; GUARRO, J. Aspergillus novoparasiticus: a new clinical species of the section Flavi. Medical Mycology, Oxford, v. 50, n. 2, p. 152-160, 2012. PMid:21745163. http://dx.doi.org/10.3109/13693786.2011.593564.

HENRY, S. H.; BOSCH, F. X.; BOWERS, J. C. Aflatoxin, hepatitis and worldwide liver cancer risks. In: DEVRIES, J. W.; TRUCKSESS, M. W.; JACKSON, L. S. (Ed.). Mycotoxins and food safety. New York: Kluwer Academic/ Plenum Publications, 2002. p. 229-320.

HUSSAIN, A.; LUTTFULLAH, G. Reduction of aflatoxin-B ${ }_{1}$ and ochratoxin-A levels in polished basmati rice (Oryza sativa Linn.) by different cooking methods. Journal of the Chemical Society of Pakistan, Karachi, v. 31, p. 911-915, 2009.

HUSSEIN, S.; BRASEL, J. M. Toxicity, metabolism, and impact of mycotoxins on humans and animals. Toxicology, Amsterdam, v. 167, n. 2, p. 101-134, 2001. PMid:11567776. http://dx.doi. org/10.1016/S0300-483X(01)00471-1.

INTERNATIONAL AGENCY FOR RESEARCH ON CANCER IARC . Some naturally occurring 12 substances: food items and constituents, heterocyclic aromatic amines and mycotoxins. Lyon: IARC Press, 1993. (IARC Monographs on the Evaluation of Carcinogenic Risks to Humans, v. 56).

INTERNATIONAL AGENCY FOR RESEARCH ON CANCER IARC. Some traditional herbal medicines, some mycotoxins, naphthalene and styrene. Lyon: IARC Press, 2002. (IARC Monographs on the Evaluation of Carcinogenic Risks to Humans, v. 82).

ITO, Y.; PETERSON, S. W.; WICKLOW, D. T.; GOTO, T. Aspergillus pseudotamarii, a new aflatoxin producing species in Aspergillus section Flavi. Mycological Research, Cambridge, v. 105, n. 2, p. 233-239, 2001. http://dx. doi.org/10.1017/S0953756200003385.

JAYARAMAN, P.; KALYANASUNDARAM, I. Natural occurrence of aflatoxins and toxigenic in rice bran oil and de-oiled bran. Indian Journal of Science and Technology, Adyar, v. 10, n. 2, p. 35-37, 2009.

KJER, J.; DEBBAB, A.; ALY, A. H.; PROKSCH, P. Methods for isolation of marine-derived endophytic fungi and their bioactive secondary products. Nature Protocols, London, v. 5, n. 3, p. 479-490, 2010. PMid:20203665. http://dx.doi.org/10.1038/ nprot.2009.233.

$\mathrm{KLICH}$, M. A.; PITT, J. I. A laboratory guide to common Aspergillus species and their Teleomorphs. Sydney: CSIRO Division of Food Science and Technology, 1988.

KUIPER-GOODMAN, T. Food safety: mycotoxins and phycotoxins in perspective. In: MIRAGLIA, M.; VAN EGMOND, H. P.; BRERA, C.; GILBERT, J. (Ed.). Mycotoxins and phycotoxins developments in chemistry, toxicology and food safety. Ft. Collins: Alaken, Inc., 1998. p. 213-231. 
MAKUN, H. A.; DUTTON, M. F.; NJOBEH, P. B.; MWANZA, M.; KABIRU, A. Y. Natural multi-occurrence of mycotoxins in rice from Niger State, Nigeria. Mycotoxin Research, Heidelberg, v. 27, n. 2, p. 97-104, 2011. PMid:21836766. http://dx.doi.org/10.1007/ s12550-010-0080-5.

MCLEAN, J.; DAWE, D.; HARDY, B.; HETTEL, G. Rice almanac: source book for the most important economic activity on earth. Los Baños: IRRI, 2002. p. 298.

MOSS, M. O. Risk assessment for aflatoxins in foodstuffs. International Biodeterioration \& Biodegradation, Barking, v. 50, n. 3-4, p. 137-142, 2002. http://dx.doi.org/10.1016/S09648305(02)00078-1.

MURAKAMI, H. Classification of the koji mold. The Journal of General and Applied Microbiology, Tokyo, v. 17, n. 4, p. 281-309, 1971. http://dx.doi.org/10.2323/jgam.17.281.

OK, H. E.; KIM, D. M.; KIM, D.; CHUNG, S. H.; CHUNG, M. S.; PARK, K. H.; CHUN, H. S. Mycobiota and natural occurrence of aflatoxin, deoxynivalenol, nivalenol and zearalenone in rice freshly harvested in South Korea. Food Control, Guildford, v. 37, n. 1, p. 284-291, 2014

PARK, J. W.; CHOI, S. Y.; HWANG, H. J.; KIM, Y. B. Fungal mycoflora and mycotoxins in Korean polished rice destined for humans. International Journal of Food Microbiology, Amsterdam, v. 103, n. 3, p. 305-314, 2005. PMid:16099315. http://dx.doi.org/10.1016/j.ijfoodmicro.2005.02.001.

PARK, J. W.; KIM, E. K.; KIM, Y. B. Estimation of the daily exposure of Koreans to aflatoxin B1 through food consumption. Food Additives and Contaminants, London, v. 21, n. 1, p. 70-75, 2004. PMid:14744682. http://dx.doi.org/10.1080/02652 030310001622782 .

PARK, J. W.; KIM, Y. B. Effect of pressure cooking on aflatoxin $B_{1}$ in rice. Journal of Agricultural and Food Chemistry, Washington, v. 54, n. 6, p. 2431-2435, 2006. PMid:16536630. http://dx.doi. org/10.1021/jf053007e.

PETERSON, S. W.; ITO, Y.; HORN, B. W.; GOTO, T. Aspergillus bombycis, a new aflatoxigenic species and genetic variation in its sibling species, A. nomius. Mycologia, New York, v. 93, n. 4, p. 689-703, 2001. http://dx.doi.org/10.2307/3761823.

PILDAIN, M. B.; FRISVAD, J. C.; VAAMONDE, G.; CABRAL, D.; VARGA, J.; SAMSON, R. A. Two new aflatoxin producing Aspergillus species from Argentinean peanuts. International Journal of Systematic and Evolutionary Microbiology, Reading, v. 58, n. Pt 3, p. 725-735, 2008. PMid:18319485. http://dx.doi. org/10.1099/ijs.0.65123-0.

PITT, J. I.; HOCKING, A. D. Fungi and food spoilage. New York: Springer Science Business Media, 2009.

PITT, J. I.; TANIWAKI, M. H.; COLE, M. B. Mycotoxin production in major crops as influenced by growing, harvesting, storage and processing, with emphasis on the achievement of food safety objectives. Food Control, Guildford, v. 32, n. 1, p. 205-215, 2013. http://dx.doi.org/10.1016/j.foodcont.2012.11.023.

PRIETTO, L.; MORAES, P. S.; KRAUS, R. B.; MENEGHETTI, V.; FAGUNDES, C. A. A.; BADIALE-FURLONG, E. Post-harvest operations and aflatoxin levels in rice (Oryza sativa). Crop Protection, Guildford, v. 78, p. 172-177, 2015. http://dx.doi. org/10.1016/j.cropro.2015.09.011.

QIAN, G. S.; ROSS, R. K.; YU, M. C.; QIAN, G.; ROSS, R. K.; YU, M. C.; GROOPMAN, J. D. A follow-up study of urinary markers of aflatoxin exposure and liver cancer risk in Shanghai, People's Republic of China. Cancer Epidemiology, Biomarkers \& Prevention, Philadelphia, v. 3, p. 3-10, 1994.

REDDY, K. R. N.; REDDY, C. S.; MURALIDHARAN, K. Detection of Aspergillus spp. and aflatoxin B1 in rice in India. Food Microbiology, Summit-Argo, v. 26, n. 1, p. 27-31, 2009a. PMid:19028301. http://dx.doi.org/10.1016/j.fm.2008.07.013.

REDDY, K. R. N.; REDDY, C. S.; MURALIDHARAN, K. Potential of botanicals and biocontrol agents on growth and aflatoxin production by Aspergillus flavus infecting rice grains. Food Control, Guildford, v. 20, n. 2, p. 173-178, 2009b. http://dx.doi. org/10.1016/j.foodcont.2008.03.009.

SALES, A. C.; YOSHIZAWA, T. Updated profile of aflatoxin and Aspergillus section Flavi contamination in rice and its byproducts from the Philippines. Food Additives and Contaminants, London, v. 22, n. 5, p. 429-436, 2005. PMid:16019814. http:// dx.doi.org/10.1080/02652030500058387.

SANI, A. M.; AZIZI, E. G.; SALEHI, E. A.; RAHIMI, K. Reduction of aflatoxin in rice by different cooking methods. Toxicology and Industrial Health, London, v. 30, n. 6, p. 546-550, 2012. PMid:23024107. http://dx.doi.org/10.1177/0748233712462466.

SILVA, J. O.; CÂNDIDO, L. M. B.; NOVELLO, D.; MACHADO, C. Ocorrência de aflatoxinas em arroz consumido por militares do exército brasileiro por cromatografia em camada delgada e cromatografia líquida de alta eficiência. Ciência e Agrotecnologia, Lavras, v. 32, n. 4, p. 1238-1244, 2008. http://dx.doi.org/10.1590/ S1413-70542008000400031.

SOARES, C.; RODRIGUES, P.; PETERSON, S. W.; LIMA, N.; VENÂNCIO, A. Three new species of Aspergillus section Flavi isolated from almonds and maize in Portugal. Mycologia, New York, v. 104, n. 3, p. 682-697, 2012. PMid:22123651. http://dx.doi. org/10.3852/11-088.

SOCIEDADE SUL-BRASILEIRA DE ARROZ IRRIGADO - SOSBAI. Importância do arroz. In: REUNIÃO TÉCNICA DA CULTURA DE ARROZ IRRIGADO, 30., 2014, Bento Gonçalves. Anais... Santa Maria: SOSBAI, 2014. p. 9-13.

TALIGOOLA, H. K.; ISMAIL, M. A.; CHEBON, S. K. Mycobiota and aflatoxins associated with imported rice grains stored in Uganda. Czech Mycology, Brno, v. 63, n. 1, p. 93-107, 2011.

TOTEJA, G. S.; MUKHERJEE, A.; DIWAKAR, S.; SINGH, P.; SAXENA, B. N.; SINHA, K. K.; SARKAR, S. Aflatoxin B(1) contamination of 
Fungos e aflatoxinas no arroz: ocorrência e significado na saúde do consumidor

Katsurayama, A. M.; Taniwaki, M. H.

parboiled rice samples collected from different states of India: a multi-centre study. Food Additives and Contaminants, London, v. 23, n. 4, p. 411-414, 2006. PMid:16546887. http://dx.doi. org/10.1080/02652030500442490.

TRUCKSESS, M. W.; ABBAS, H. K.; WEAVER, C. M.; SHIER, W. T. Distribution of aflatoxins in shelling and milling fractions of naturally contaminated rice. Food Additives \& Contaminants. Part A, Chemistry, Analysis, Control, Exposure \& Risk Assessment, Abingdon, v. 28, n. 8, p. 1076-1082, 2011. PMid:21598135. http:// dx.doi.org/10.1080/19440049.2011.576441.

VARGA, J.; FRISVAD, J. C.; SAMSON, R. A. Two new aflatoxin producing species, and an overview of Aspergillus section
Flavi. Studies in Mycology, Baarn, v. 69, n. 1, p. 57-80, 2011. PMid:21892243. http://dx.doi.org/10.3114/sim.2011.69.05.

WALTER, M.; MARCHEZAN, E.; AVILA, L. A. Arroz: composição e características nutricionais. Ciência Rural, Santa Maria, v. 38, n. 4, p. 1184-1192, 2008. http://dx.doi.org/10.1590/S010384782008000400049 .

WANG, J.; HUANG, T.; SU, J.; LIANG, F.; WEI, Z.; LIANG, Y.; LUO, H.; KUANG, S. Y.; QIAN, G. S.; SUN, G.; HE, X.; KENSLER, T. W.; GROOPMAN, J. D. Hepatocellular carcinoma and aflatoxin exposure in Zhuqing Village, Fusui County, People's Republic of China. Cancer Epidemiology, Biomarkers \& Prevention, Philadelphia, v. 10, n. 2, p. 143-146, 2001. PMid:11219772. 